\title{
REPRESENTASI FANATISME SUPORTER SEPAK BOLA \\ PADA TOKOH UTAMA MELALUI MISE-EN-SCENE \\ DALAM PENYUTRADARAAN FILM FIKSI \\ "SETIA BERSAMAMU"
}

\author{
Rizal Jauhari \\ Dyah Arum Retnowati \\ Lilik Kustanto \\ Jurusan Film \& Televisi, Fakultas Seni Media Rekam, Institut Seni Indonesia Yogyakarta \\ Jl. Parangtritis km. 6.5 Yogyakarta Telp. (0274) 381047
}

\begin{abstract}
"Be F aithful to you" movie has been directed for sounding a new point of view of society stigma which always taking sides for negative stigma to soccer fanatic supporter. Being soccer club supporter is completely have a humanity point which loving each other and have priority to do their obligations before their rights even though being human always have minus point.

Fanaticism is more like love who can change solid things to be soft, and then, have logically considered that our self is a priority, Everything that has to do must be carefully considered, so that not become regrets in the end. That is obligation need to be a main priority before the rights has been fulfilled. This F anaticism being the foundation for directing this "Be Faithful to you" movie.

Technical consider is most effected to this movie to be implemented for being hyperbolic, so that will support fanaticism via mise-en-scene which being founded to build main character fanatically support his favorite soccer club, Like blue color is his favorite soccer club colors, that color is dominating for every setting for creating fanaticism image in his life to support that soccer club.
\end{abstract}

Keyword : directing, fanaticism, mise-en-scene, fiction movie.

Abstrak

Penyutradaraan film "Setia Bersamamu" ini menyuarakan sudut pandang baru terhadap stigma masyarakat, yang selalu memihak pada sudut pandang negatif terhadap fanatisme suporter sepakbola. Menjadi suporter sepak bola memiliki sisi manusia seutuhnya yang saling mencintai dan memiliki prioritas kewajiban sebelum menjalankan haknya walaupun banyak kekurangan menjadi manusia seutuhnya.

Fanatisme diibaratkan seperti cinta yang dapat mengubah hal keras menjadi lembut, yang kemudian memiliki pertimbangan logis bahwasannya diri sendiri adalah prioritas kehidupan, semua yang akan dijalankan harus dipertimbangkan matang-matang agar tidak berakhir penyesalan, bahwasannya prioritas kewajiban menjadi utama sebelum haknya terpenuhi. Bentuk fanatisme tersebut yang menjadi pondasi dalam penyutradaraan film Setia Bersamamu.

Pertimbangan teknis sangat berpengaruh dalam film ini yang diimplementasikan secara hiperbola untuk mendukung konsep fanatisme melalui konsep mise-en-scene yang menjadi pondasi untuk membangun karakter utama yang secara fanatis mendukung tim favoritnya, seperti warna biru muda yang mendominasi pada setiap setting menjadi bentuk fanatisme tokoh utama dalam kehidupannya mendukung tim favoritnya sebagai warna identitas tim.

Kata Kunci : Penyutradaraan, Fanatisme, Mise-en-scene, Film Fiksi 


\section{Rizal Jauhari, Dyah Arum Retnowati, Lilik Kustanto}

Representasi Fanatisme Suporter Sepak Bola melalui Mise-en-scene dalam Penyutradaraan Film Fiksi

\section{Pendahuluan}

Lamongan adalah sebuah Kabupaten yang terletak di Jawa Timur, secara geografis Kabupaten Lamongan terletak pada 6051' $7^{\circ} 23^{\prime}$ Lintang Selatan dan $112^{\circ} 33^{\prime}-112^{\circ} 34$ Bujur Timur. Kabupaten Lamongan memiliki luas wilayah kurang lebih $1.812,8 \mathrm{~km}^{2}$ atau $\pm 3.78 \%$ dari luas wilayah Provinsi Jawa Timur. Dengan panjang garis pantai sepanjang $47 \mathrm{~km}$, maka wilayah perairan laut Kabupaten Lamongan adalah seluas $902,4 \mathrm{~km}^{2}$, apabila dihitung 12 mil dari permukaan laut. Berbicara tentang Kabupaten Lamongan, tentunya tidak lepas dari wisata dan kuliner. Wisata di Lamongan sangat banyak dan beragam mulai dari wisata bahari yang diwakilkan oleh Wisata Bahari Lamongan sampai dengan wisata religi yaitu Makam Sunan Drajat dan masjid namira yang menjadi ikon dari Kabupaten Lamongan. Dari segi kuliner pecel lele dan soto Lamongan lah yang sudah sangat melegenda bahkan diseluruh pelosok Indonesia sangat mudah untuk menemui kedua makanan tersebut, akan tetapi tidak hanya itu saja ada wingko babat dan sego boran yang sudah terbukti keasliannya dari Kabupaten Lamongan. Satu hal yang juga sering dibanggakan oleh warga Lamongan pada beberapa tahun terakhir adalah tim sepak bolanya yaitu Persela Lamongan. Persela Lamongan mulai melambung namanya sejak 2003 yaitu ketika Persela bisa lolos ke Divisi Utama Liga Indonesia, di era ini lah banyak suporter Persela bermunculan, mereka di juluki dengan nama LA Mania atau Lamongan Asli Mania. Melalui hal-hal tersebutlah yang melatarbelakangi terbentuknya karya dan sebagai wujud memperkenalkan serta mempopulerkan Kabupaten Lamongan kepada masyarakat luas melalui media film fiksi.

Penciptaan film fiksi "Setia Bersamamu" yang berkisah tentang seorang capo atau seorang dirigen suporter Persela Lamongan dan juga seorang penjual pecel lele yang bernama Hasan. Hasan memiliki seorang istri bernama Yanti yang sedang hamil tua dan sangat butuh perhatian dan kasih sayang dari sang suami. Sampai pada akhirnya terjadi pertandingan terakhir bagi Persela Lamongan, pertandingan yang akan menentukan persela akan degradasi atau tidak, dan pada hal itu juga bertepatan dengan masa-masa dimana Yanti kemungkinan akan melahirkan anaknya. Hasan bingung antara memilih memimpin teman-temannya untuk mendukung Persela Lamongan atau menemani istrinya yang akan melahirkan.

Film ini dirasa tepat untuk menceritakan kisah kepada masyarakat tentang menjauhnya hubungan seorang suami dan istrinya ataupun seorang pemimpin kepada pengikutnya. Karena film adalah media informasi dan hiburan, media dari sebuah pesan yang ingin disampaikan kepada masyarakat luas tentang gambaran, gagasan, informasi, ungkapan atau ekspresi 
yang dapat dibicarakan, ditelaah sebagai wacana dari proses gerak peradaban manusia. Film merupakan bentuk semua dari kehidupan dengan simbol-simbol dan aktivitas imajinatif juga kekuatan teknologi. Tercipta sebuah pesan yang menunjukan realitas yang memberikan harmoni ataupun sekedar menghibur.

Penonton tidak hanya di sajikan cerita dengan dramatik serta adegan yang kuat di film drama olahraga "Setia Bersamamu" namun diberikan pengalaman menonton yang berbeda dari segi visual dengan penerapan mise-en-scene yang dihadirkan sebagai representasi atau bentuk yang mewakili suporter sepak bola pada sosok tokoh utama. Melalui penggunaan mise-enscene penonton akan lebih mengerti lebih jauh lagi tentang suporter sepak bola.

Ide penciptaan "Representasi fanatisme suporter sepak bola pada tokoh utama melalui mise-en-scene" bermula dari hobi bermain dan menonton sepak bola dan menemukan hal unik untuk diangkat menjadi skenario yaitu suporter sepak bola, kemudian mengembangkan ide menjadi skenario, setelah skenario jadi menganalisis karakter, konflik, dan plot yang terdapat pada skenario film "Setia Bersamamu". Penggunaan representasi akhirnya dipilih untuk menjadi konsentrasi pada aspek penyutradaraan untuk menyampaikan dan mewakili keadaan dan kondisi suporter pada utama. Setelah mencari konsep penyutradaraan dan film yang dapat diterapkan sebagai referensi, pada akhirnya menemukan Film berjudul "Darah Biru Arema" karya Taufan Agustyan yang menerapkan mise-en-scene dalam merepresentasikan seorang suporter sepak bola pada tokoh utama. Pada akhirnya muncul ide untuk menggunakan konsep representasi fanatisme suporter sepak bola pada tokoh utama dengan menggunakan mise-en-scene.

\section{Objek Penciptaan}

\section{Fanatisme}

Fanatisme adalah suatu keyakinan atau suatu pandangan tentang sesuatu, yang positif atau yang negatif, pandangan yang tidak memiliki sandaran teori atau pijakan kenyataan, tetapi dianut secara mendalam sehingga susah diluruskan atau diubah. Menurut definisinya, fanatisme biasanya tidak rasional atau keyakinan seseorang yang terlalu kuat dan kurang menggunakan akal budi sehingga tidak menerima faham yang lain dan bertujuan untuk mengejar sesuatu. Adanya fanatisme dapat menimbulkan perilaku agresi dan sekaligus memperkuat keadaan individu yang mengalami deindividuasi untuk lebih tidak terkontrol perilakunya. Pengertian Fanatisme sendiri dapat disebut sebagai orientasi dan sentimen yang mempengaruhi seseorang dalam :

a. Berbuat sesuatu, menempuh sesuatu atau memberi sesuatu,

b. Dalam berfikir dan memutuskan 


\section{Rizal Jauhari, Dyah Arum Retnowati, Lilik Kustanto}

Representasi Fanatisme Suporter Sepak Bola melalui Mise-en-scene dalam Penyutradaraan Film Fiksi

c. Dalam mempersepsi dan memahami sesuatu, dan dalam merasa secara psikologis, seseorang yang fanatik biasanya tidak mampu memahami apa-apa yang ada di luar dirinya, tidak faham terhadap masalah orang atau kelompok lain, tidak mengerti faham atau filsafat selain yang mereka yakini

\section{L.A Mania (Suporter Persela}

\section{Lamongan)}

LA Mania atau Lamongan Asli Mania adalah suporter dari klub kesebelasan Persela Lamongan yang memiliki banyak sekali anggota yang tersebar di Indonesia, LA Mania berdiri pada tanggal 18 Januari 2001. Anggota dari LA Mania kebanyakan adalah seorang pedagang pecel lele, mahasiswa, pelajar, dan lain sebagainya. LA Mania sering mendukung tim kebangaan Persela bermain dimanapun seperti halnya ketika bermain di Malang, Jakarta, Yogyakarta, Medan, Makassar, bahkan sampai Serui Jayapura pun mereka selalu ada untuk Persela.

\section{Konsep Karya}

Film fiksi "Setia Bersamamu" menekankan pada aspek cara berpikir kreatif dalam menceritakan dan menuturkan suatu kejadian, dengan menggunakan mise-enscene yang merupakan bentuk cara pengemasan film dengan tujuan untuk merepresentasikan suporter sepak bola pada tokoh utama, maka ada proses seorang sutradara memberikan batasan kepada aktor untuk memerankan tokoh, batasan dalam hal ini agar tokoh utama tidak melewati batas dan bertujuan memperoleh pergerakan serta dialog yang dikonsepkan. Konsep penyutradaraan yang digunakan dalam film fiksi "Setia Bersamamu" lebih menekankan pada konsep mise-en-scene sebagai representasi suporter sepak bola pada tokoh utama.

Salah satu aspek untuk membangun mise-en-scene adalah acting dari pemain. Sutradara mengarahkan tokoh utama agar bisa merepresentasikan suporter sepak bola terkhusus supporter Persela Lamongan. Fanatisme dan loyalitas suporter yang akan di bentuk pada tokoh utama yang didukung dengan dialog dan logat jawa timuran serta ekspresi, perubahan emosi dan gesture tubuh sangat diperhatikan untuk menunjang konsep tersebut. Ekspesi, perubahan emosi, dan gesture tubuh akan dibuat natural dengan cara tokoh utama terjun langsung ke lapangan, seperti menonton pertandingan secara langsung dan belajar kepada sang capo asli serta menjadi capo saat pertandingan berlangung, hal ini bertujuan agar tokoh utama dapat merasakan langsung rasanya menjadi capo. Tujuan acting dibuat natural agar dapat mendekatkan tokoh utama dengan penonton.

Pemilihan tokoh utama atau casting, pemain yang dipilih adalah pemain yang sudah pernah atau masih menjadi anggota suporter sepak bola dan pernah belajar teater, 
hal ini bertujuan agar tokoh utama dapat merepresentasikan suporter sepak bola dengan baik. Selain itu tokoh utama juga akan melakukan workshop dan riset sang tokoh utama tentang suporter sepak bola terutama karakteristik dari capo agar tokoh utama semakin baik lagi dalam merepresentasikan suporter sepak bola.

Film "Setia Bersamamu" tetap pada film umumnya yang menghadirkan realitas di dalam film, namun diperkuat dengan genre yang diangkat adalah drama, dan tema yang diangkat adalah mengenai sepak bola. Mengapa drama dan sepak bola karena karakter utama disepanjang film menekankan tekad bahwa kesetiaan untuk mendukung klub kebanggaannya Persela Lamongan secara langsung, akan tetapi keinginannya untuk selalu mendukung klub kebanggan terhalang oleh sang istri yang sedang hamil tua dan sangat butuh kasih sayang dari sang suami, sampai dimana sang karakter utama harus dapat memilih untuk menemani istrinya yang akan melahirkan atau memimpin teman-temannya untuk mendukung Persela berlaga di laga penentuan.

Mise-En-Scene dalam film ini ditekankan pada pendukung konsep utama yaitu representasi seorang suporter sepak bola. Mise-en-scene yang muncul pada film ini tentunya berhubungan dengan Persela Lamongan dan Kabupaten Lamongan. Melalui mise-en-scene penonton akan dapat mendapatkan informasi tentang tokoh yang sedang bermain yaitu seorang suporter sepak bola yang juga merupakan pedagang pecel lele, peristiwa apa yang sedang terjadi yaitu halangan seorang suporter sepak bola yang ingin mendukung timnya berlaga, tempat berlangsungnya peristiwa yaitu di Kabupaten Lamongan Jawa Timur, dan merasakan semua yang ada di dalam layar.

\section{Setting atau latar}

Setting memiliki fungsi sebagai pemberi informasi kepada penonton latar dan waktu dari sebuah peristiwa itu terjadi. Setting dalam film pendek "Setia Bersamamu" ini terjadi di Kabupaten Lamongan Jawa Timur pada tahun 2019, pada saat itulah Persela Lamongan harus berjuang dengan keras untuk keluar dari zona degradasi dan suporter juga diuji kesetiaannya dalam mendukung Persela Lamongan secara langsung di stadion, oleh karena itu setting yang diambil pada film pendek "Setia Bersamamu" ini meliputi Stadion Surajaya Lamongan, basecamp LA Mania, Alun-alun Lamongan, pedesaan di Kabupaten Lamongan, serta warung pecel lele.

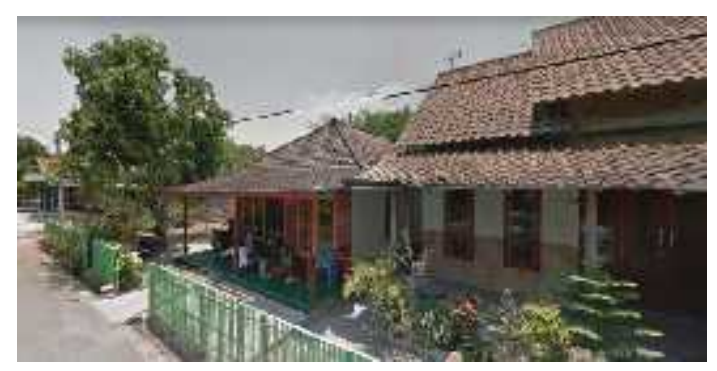

Gambar 1. Rumah di Desa Tracal Lamongan (Sumber : Google Maps, diakses pada 1 April 2019) 


\section{Rizal Jauhari, Dyah Arum Retnowati, Lilik Kustanto}

Representasi Fanatisme Suporter Sepak Bola melalui Mise-en-scene dalam Penyutradaraan Film Fiksi

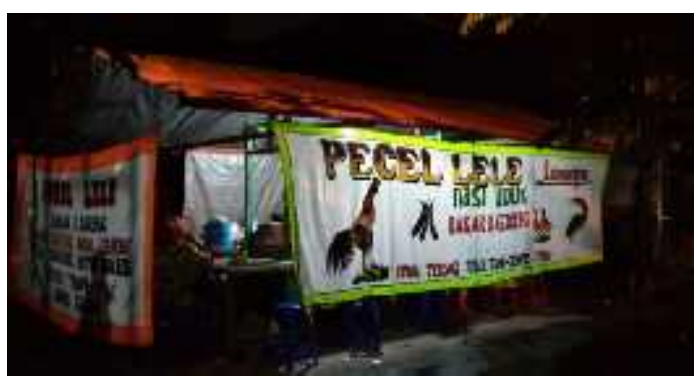

Gambar 2. Warung pecel lele

(Sumber : Brilio.net, diakses pada 20 Februari 2019)

Setting rumah yang akan digunakan di dalam film "Setia Bersamamu" adalah rumah sederhana menengah ke bawah yang berada di sebuah desa. Rumah ini milik Hasan dan Yanti yang sudah ditinggali sejak mereka menikah.

Setting warung pecel lele milik Hasan seperti warung pecel lele pada umumnya yang berada di pinggir jalan dan masih menggunakan tenda sebagai atapnya dan spanduk pecel lele Lamongan yang khas.

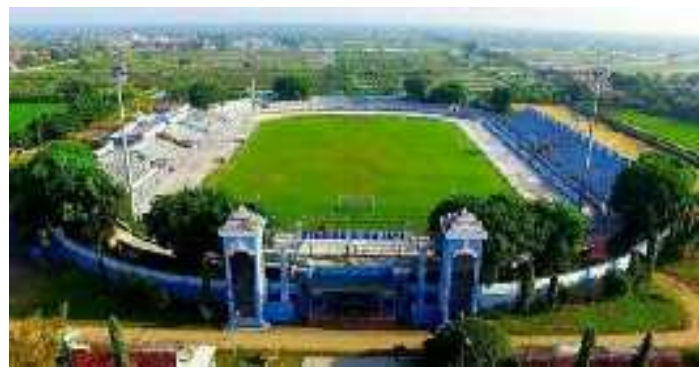

Gambar 3. Stadion Surajaya Lamongan (Sumber : Instagram/PerselaFC, diakses pada 20 Februari 2019)

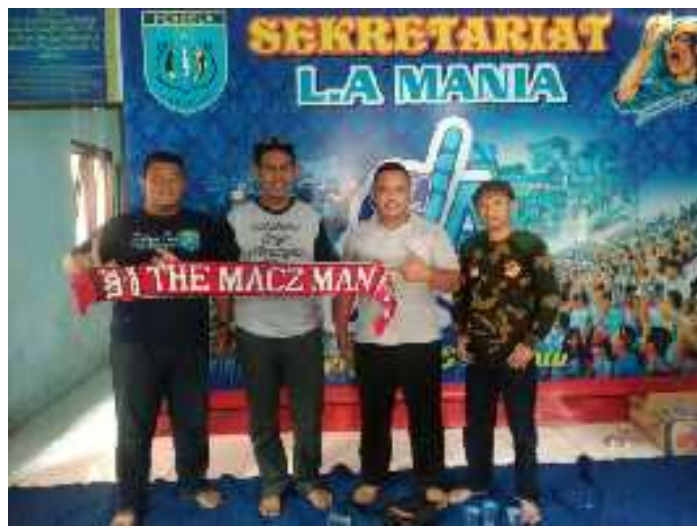

Gambar 4. basecamp LA Mania

(Sumber :twitter/PSMSurabaya, diakses pada 20 Juni 2020)

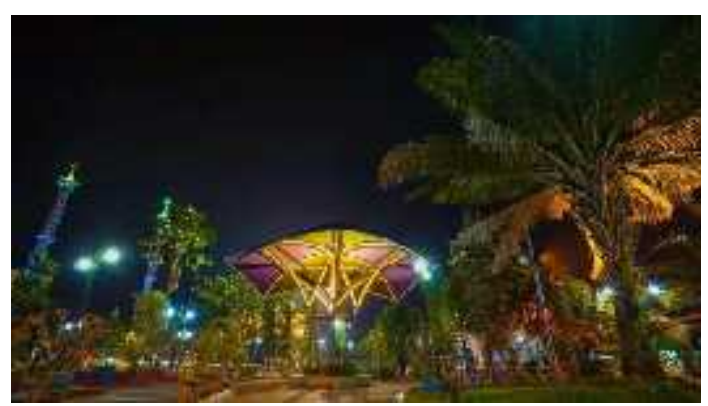

Gambar 5. Alun-alun Lamongan

(Sumber : keluyuran.com/tempat-wisata-dilamongan/, diakses pada 20 Juni 2020)

Setting di stadion akan memakai stadion asli yaitu stadion Surajaya Lamongan yang berada di Kabupaten Lamongan.

Setting basecamp LA Mania berada di area komplek stadion Surajaya Lamongan dan memiliki satu bangunan tersendiri.

\section{Make up dan wardrobe}

Penataan make up dan wardrobe dalam film ini berfungsi untuk membangun karakter dari masing-masing tokoh yang akan dibangun dengan tingkat ekonomi menengah ke atas yang tinggal di pedesaan. Make up korektif digunakan agar masing-masing tokoh terlihat natural seperti masyarakat pedesaan pada umumnya yang cenderung jarang memakai make up. Penggunaan wardrobe untuk tokoh utama yaitu Hasan dan teman LA Mania yaitu Iwan akan memakai kaos, jersey, dan atribut Persela Lamongan untuk merepresentasikan seorang suporter sepak bola yang sangat fanatik terhadap klub kebanggaanya, sedangkan sang Yanti akan memakai daster yang sesuai dengan kultur masyarakat pedesaan di Lamongan pada umumnya, selain itu Yanti akan memakai dress dikala bepergian keluar rumah. 


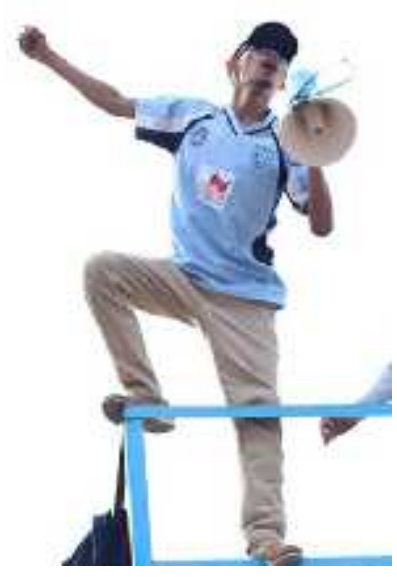

a

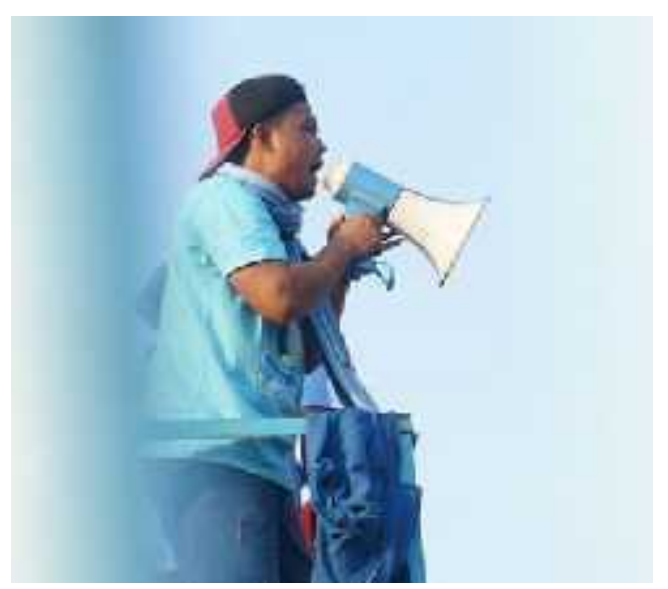

$\mathrm{b}$

Gambar 6. a-b Contoh referensi wardrobe Hasan

(Sumber : Jawa Pos, diakses pada 11 April 2019)

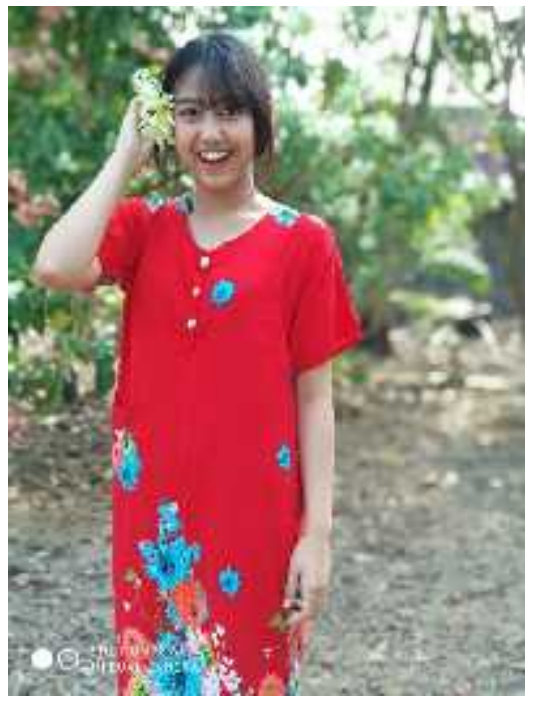

Gambar 7. Contoh referensi wardrobe Yanti (Sumber : twitter/fransiskasaraswati, diakses pada 3 April 2019)

\section{Pencahayaan}

Tata cahaya dalam film ini menggunakan 2 sumber cahaya yaitu matahari dan lampu (buatan). Cahaya buatan akan menggunakan konsep futuristik, dimana cahaya lampu buatan akan dibuat warnawarni sesuai dengan warna triadic yaitu warna biru muda, kuning, dan merah muda yang sudah dikonsepkan sebagai color palette sesuai dengan color palette tim
Persela Lamongan dan juga untuk mendukung suasana hati sang tokoh utama yang sedang mengalami kebimbangan.

\section{Pengadeganan}

Seperti pada di konsep penyutradaraan, pengadeganan akan dibuat sang tokoh utama dibentuk untuk merepresentasikan suporter sepak bola dengan cara adegan akan dibuat secara realistis sesuai dengan keadaan sebenarnya yang terjadi, maka dari itu riset sangat penting bagi sang tokoh utama tentang supporter sepak bola terutama karakteristik dari capo atau sang pemimpin nyanyian, yelyel, yang nantinya juga akan ada workshop agar tokoh utama dapat merepresentasikan suporter sepak bola dengan baik.

\section{Pembahasan Karya}

Penerapan representasi fanatisme suporter sepak bola melalui mise en scene merupakan konsep utama yan diterapkan dalam film pendek "Setia Bersamamu". Secara garis besar mise-en-scene adalah segala sesuatu yang terlihat secara kasat mata di layar dan 


\section{Rizal Jauhari, Dyah Arum Retnowati, Lilik Kustanto}

Representasi Fanatisme Suporter Sepak Bola melalui Mise-en-scene dalam Penyutradaraan Film Fiksi

meletakan sesuatu di dalam peristiwa yang dibuat. Unsur dalam mise-en-scene yang akan dibuat meliputi dari setting, lighting, make up dan wardrobe, serta acting atau pergerakan. Dengan adanya mise-en-scene ini sutradara dapat merepresentasikan fanatisme seorang suporter sepak bola sesuai dengan konsep tersebut.

a. Eksposisi / Pengenalan

Film pendek berjudul "Setia

Bersamamu" ini dibuka dengan tokoh utama yang memiliki dua kecintaan dalam hidupnya, yaitu sepakbola dan istrinya. Dua hal tersebut tentunya dapat mewakili beberapa stigma masyarakat bahwa menjadi suporter berdampak negatif pada kehidupannya. Stigma tersebut dalam film ini disampaikan melalui tokoh Yanti yang menjadi istri Hasan. Dirinya melarang keras Hasan untuk menjadi capo atau dirijen suporter sepakbola, namun kecintaannya pada sepakbola membuat Hasan tidak dapat berhenti mendukung tim kesebelasannya untuk sampai pada pertandingan penentuan. Perkenalan karakter Hasan yang merepresentasikan seorang suporter sepak bola digambarkan melalui Hasan yang dimanapun dan kapanpun selalu menonton pertandingan sepak bola walaupun hanya melalui layar ponselnya dan tidak bisa menyaksikan pertandingan secara langsung di Stadion, Hasan sampai rela menaiki kursi demi menghayati dirinya sebagai seorang capo, dan untuk menggambarkan karakter Hasan yang sangat fanatik sekali dengan tim kebanggaanya Persela Lamongan, Hasan selalu mengenakan baju maupun jersey Persela Lamongan dimanapun dan kapanpun berada yang terjadi pada scene kedua.

b. Turning Point 1

Setelah konflik antar dua karakter terlihat, pada turning point pertama, keinginan karakter diperlihatkan lebih gamblang, yang memiliki dua keinginan yaitu menonton pertandingan untuk memimpin suporter dalam pertandingan penentuan atau memilih menuruti keinginan istrinya untuk selalu menemani istrinya hingga proses persalinan anak pertamanya yang sebelumnya pernah gagal dan istrinya keguguran, seperti yang terjadi pada scene keempat, keinginan Hasan untuk mencapai misi pertamanyanya diperlihatkan ketika Hasan datang ke basecamp LA Mania, dimana Setting basecamp terdapat benderabendera masing-masing koordinator wilayah, bassdrum, poster penyemangat, syal, dan stiker, serta motor-motor dengan plat nomor $\mathrm{S}$ yang merupakan plat nomor dari Kabupaten Lamongan, keinginan Hasan untuk menonton pertandingan secara langsung di Stadion semakin memuncak ketika tokoh Iwan mempengaruhi Hasan untuk tetap dapat hadir dalam pertandingan final Persela, hal tersebut menambah konflik tokoh utama untuk harus memilih dua pilihan yang sulit, yaitu memilih menuruti istrinya untuk tidak menonton pertandingan, atau memilih keinginan egonya untuk menonton pertandingan final Persela. 


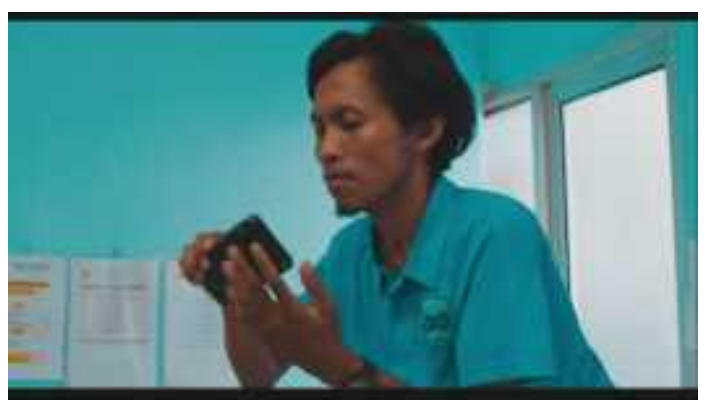

Gambar 8. Screenshot film "Setia Bersamamu" untuk menunjukan acting dan wardrobe

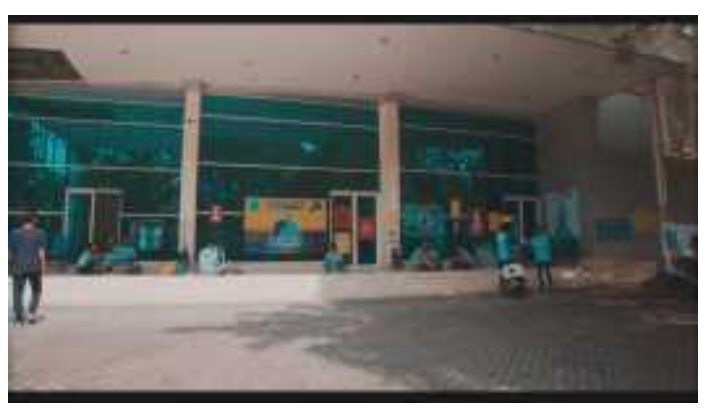

Gambar 9. Screenshot film "Setia Bersamamu" untuk menunjukan acting dan setting

\section{c. $\quad$ Turning Point 2}

Turning point kedua konflik semakin memuncak, dalam scene tujuh perbincangan yang terjadi pada kamar Hasan dan Yanti. Hasan memberanikan diri untuk mencoba meminta izin pada Yanti untuk menonton pertandingan agar keinginannya bisa berjalan baik dan dirinya dapat memimpin suporter dengan tenang. Namun Yanti dengan trauma masa lalunya dengan bayinya yang pernah gagal untuk lahir, membuat Yanti tetap bersikukuh untuk melarang Hasan menonton pertandingan. Setting kamar Hasan yang fanatik dengan Persela Lamongan ditunjukan dengan adanya poster legenda Persela yaitu Choirul Huda, syal Persela Lamongan, stiker Persela Lamongan, serta foto-foto saat Hasan mendukung Persela Lamongan. Scene ketujuh warna cahaya daylight memberi kesan suasana yang dingin dan canggung antar dua karakter yaitu Hasan dan Yanti.

Hal tersebut berlanjut pada konflik internal yang hadir dalam diri Hasan, bagaimana dirinya ingin melihat tim kesebelasan favoritnya bertanding di puncak kompetisi final yang belum pernah diraih sebelumnya, namun Yanti yang secara posesif dan membutuhkan Hasan untuk menemani masa kehamilannya melarang Hasan untuk pergi mendukung tim favoritnya. Scene kedelapan ini Hasan memakai jersey Persela Lamongan yang menunjukan fanatisme seorang suporter sepak bola. Terdapat syal Persela Lamongan diatas akuarium Hasan yang merupakan tempat merenung Hasan, ikan dalam akuarium adalah ikan lele yang merupakan icon dari Kabupaten Lamongan dan juga Persela Lamongan. Scene kedelapan menggambarkan kebimbangan pada karakter Hasan, dua pilihan sulit yang terus membuat hatinya bergejolak dan kalut digambarkan melalui warna cahaya akuarium yang berubah dan merefleksikan dirinya.

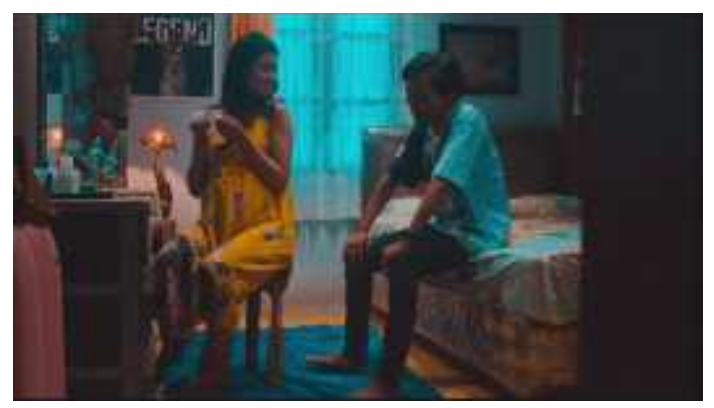

Gambar 10. Screenshot film "Setia Bersamamu" untuk menunjukan acting, setting, lighting, dan make up wardrobe. 


\section{Rizal Jauhari, Dyah Arum Retnowati, Lilik Kustanto}

Representasi Fanatisme Suporter Sepak Bola melalui Mise-en-scene dalam Penyutradaraan Film Fiksi

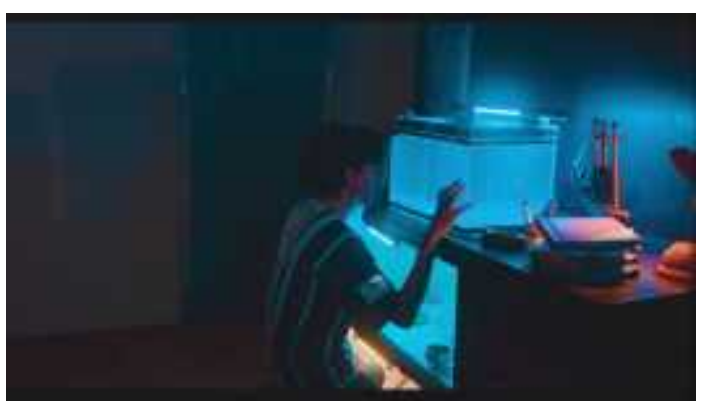

Gambar 11. Screenshot film "Setia Bersamamu" untuk menunjukan lighting

Pada akhirnya Hasan tetap berangkat untuk menonton pertandingan Persela Lamongan secara langsung di Stadion. Suasana euforia pertandingan penentuan yang ditunggu-tunggu oleh Hasan digambarkan melalui scene sebelas dengan penuh antusias dari Hasan dan lingkungan sekitarnya yang menjadi salah satu tujuannya yaitu menonton laga pertandingan penentuan tim Persela Lamongan. Hasan bersorak, bernyanyi, melakukan koreografi dalam memimpn teman-teman LA Manianya dalam mendukung Persela Lamongan. Scene kesebelas ini Hasan memakai jersey Persela Lamongan beserta syal yang dibetangkan dan juga membawa megaphone untuk mendukung tim Persela Lamongan berlaga, suasana stadion yang meriah dengan euphoria LA Mania. Pada saat yang bersamaan kembali menaikan konflik dramatik yang lebih tinggi, yang di sisi lain ketika Hasan menonton pertandingan, Yanti tiba-tiba akan melahirkan diluar prediksi tanggal yang ditetapkan dokter saat di USG. Yanti merasa pecah ketuban dan membuat keadaan semakin kalut.

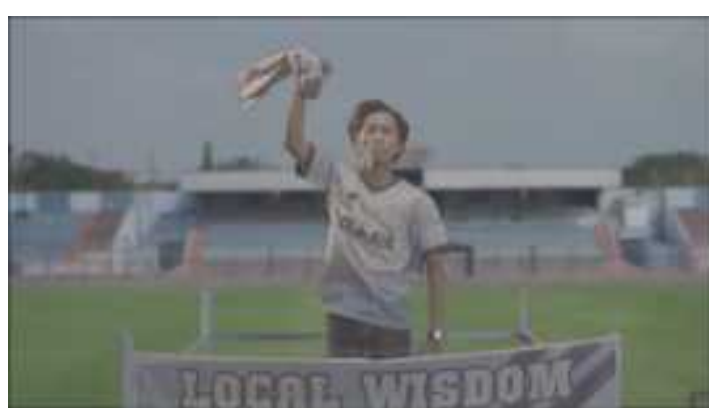

Gambar 12. Screenshot film "Setia Bersamamu" untuk menunjukan acting dan setting

d. Resolusi / Penyelesaian

Pada babak penyelesaian, layaknya kehidupan, Hasan dihadapkan dengan dua pilihan yang sulit, dan harus memilih untuk mengikuti egonya agar dapat melanjutkan menonton pertandingan hingga tim favoritnya mengangkat piala atau merelakan egonya untuk memenuhi kewajiban dan kecintaannya bersama istrinya. Sehingga ketika setengah pertandingan selesai, Hasan mendapat kabar mengenai istrinya yang akan melahirkan, yang membuat dirinya memilih merelakan egonya untuk memenuhi kewajibannya dengan segera bergegas menemani proses persalinan anak pertamanya dengan Yanti. Kehadiran Hasan dalam mengutamakan kewajiban untuk menemani istrinya, menjadi fanatisme yang logis, bagaimana hak seseorang dapat hadir dan terpenuhi setelah menyelesaikan kewajibannya. Pada akhirnya Hasan tetap menjalankan dua keluarga dalam konteks yang berbeda, tim favoritnya serta istri dan buah hati yang ia cintai. Scene delapan belas menggambarkan kehangatan antara Hasan dan Yanti dengan tambahan lampu warna merah sehingga menambah kesan romantis. 
Lampu warna biru dari luar jendela yang merefleksikan mengimpretasikan ketenangan dalam hubungan mereka ketika mereka saling bersama.

\section{Kesimpulan}

Representasi suporter sepak bola pada tokoh utama melalui mise-en-scene pada film fiksi "Setia Bersamamu" telah diwujudkan dalam proses yang sangat panjang dan kompleks. Proses diawali dengan hobi menonton pertandingan sepak bola Persela Lamongan secara langsung, mengamati beberapa hal unik yang ditemukan pada saat menonton pertandingan sepak bola, salah satunya adalah mengenai suporter sepak bola Persela Lamongan yaitu LA Mania. LA Mania merupakan suporter fanatik dari tim Persela Lamongan yang dimanapun Persela Lamongan bertanding LA Mania selalu ada karena kalangan suporter Persela Lamongan bermacam-macam seperti, Mahasiswa, Pedagang Pecel Lele, maupun dari warga biasa. Sekelompok suporter tersebut pasti memiliki pemimpin yaitu seorang capo atau pemimpin suporter dalam mendukung tim kesayangan berlaga, melalui capo inilah menjadi ide dari film fiksi "Setia Bersamamu".

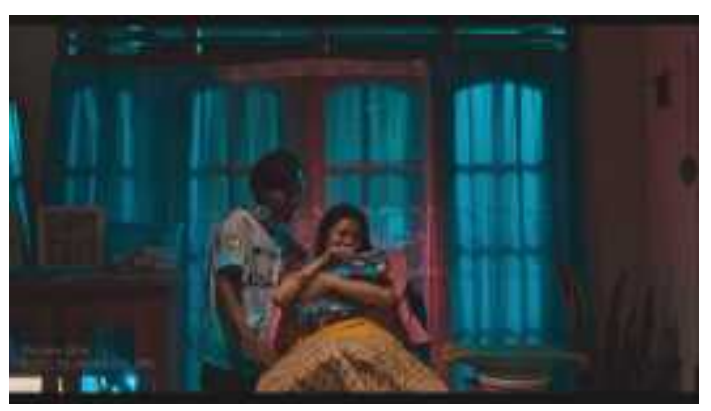

Gambar 13. Screenshot film "Setia Bersamamu" untuk menunjukan lighting
Representasi adalah mendeskripsikan atau memunculkan gambaran dari suatu objek, dalam film fiksi "Setia Bersamamu" ini objek yang dipilih adalah seorang suporter sepak bola yang sangat fanatik sekali terhadap klub kesayangannya. Representasi fanatisme suporter sepak bola didukung oleh konsep mise-en-scene yang dapat membuat representasi fanatisme suporter sepak bola dapat diterima dengan mudah oleh penonton. Konsep mise-en-scene yang digunakan adalah setting, make up dan wardrobe, lighting, serta acting atau pengadeganan.

$$
\text { Mise-en-scene yang digunakan }
$$
meliputi setting tempat di Kabupaten Lamongan dan setting waktu di tahun 2019. Make up memakai make up korektif yang digunakan agar tokoh dalam film fiksi "Setia Bersamamu" ini sesuai dengan masyarakat pedesaan pada umumnya, sedangkan wardrobe yang digunakan memakai baju dan jersey Persela Lamongan agar dapat merepresentasikan fanatisme seorang suporter sepak bola. Lighting yang digunakan menggunakan konsep lighting futuristic dengan warna triadic biru muda, kuning, dan merah muda. Acting atau pengadeganan dikonsepkan dengan menggunaka dialog dan logat bahasa Jawa Timur dengan secara khusus dialog dan logat Lamongan.

Kesimpulan yang didapat dari film fiksi "Setia Bersamamu" ini adalah menyampaikan sudut baru terhadap stigma masyarakat yang selalu memihak pada sudut 


\section{Rizal Jauhari, Dyah Arum Retnowati, Lilik Kustanto}

Representasi Fanatisme Suporter Sepak Bola melalui Mise-en-scene dalam Penyutradaraan Film Fiksi

pandang negatif terhadap fanatisme suporter

sepak bola, bahwa menjadi suporter tidak melulu hanya tentang teriakan yang menggebu untuk mendukung tim favoritnya, tidak hanya berkerumun ramai bahkan hingga adu fisik dengan suporter yang menjadi tim lawan favoritnya. Menjadi suporter sepak bola memiliki sisi manusia seutuhnya yang saling mencintai dan memiliki prioritas kewajiban sebelum menjalankan haknya walaupun banyak kekurangan menjadi manusia seutuhnya. Fanatisme dalam film ini diibaratkan seperti cinta yang memiliki pertimbangan logis bahwasannya diri sendiri adalah prioritas kehidupan, semua yang akan dijalankan harus dipertimbangkan matang-matang agar tidak berakhir penyesalan, bahwasannya prioritas kewajiban menjadi utama sebelum haknya terpenuhi.

\section{Daftar Pustaka}

Boggs, Joseph M. terjemahan Asrul Sani. 1992. Cara Menilai Sebuah Film (The Art of Watching Film). Jakarta: Yayasan Citra

Bordwell, David. 2015. Film Art An Introduction Tenth Edition. Singapore: Mc Graw-Hill Education.
Dancyger, Ken. The Director's Idea: The Path to Great Directing. Oxford: Focal Press. 2006.

Fim, Miftakhul. 2015. Mencintai Sepak Bola Indonesia Meski Kusut. Yogyakarta: Indie Book Corner.

, Miftakhul. 2017. Persela Menegaskan Identitas Kami. Yogyakarta: Indie Book Corner.

Hall, Stuart.1997. Representation:Cultural Representation and Signifying Practices.London: SAGE Publications.

Harymawan, RMA. 1993. Dramaturgi. Bandung: PT Remaja Rosdakarya.

Mascelli, Joseph V. 1965. The Five C'S of Cinematography. Motion Pictures.

Pratista, Himawan. 2008. Memahami Film. Yogyakarta: Homerian Pustaka.

Proferes, Nicholas T. 2001. Film Directing Fundamental. Burlington: Focal Press.

Sani, Drs. Asrul. 1992. Cara Memahami Sebuah Film. Jakarta: Yayasan Citra.

Sumarno, Marselli. 1996. Dasar Dasar Apresiasi Film. Jakarta: Gramedia Rasindo.

Widagdo, Bayu M. \& Winastyawan, Gora S. (2004). Bikin Sendiri Film Kamu: Panduan Produksi Film Indonesia. Yogyakarta.

Zoebazary, Ilham. 2010. Kamus istilah Televisi \& Film. Jakarta: PT. Gramedia Pustaka Tama 